\title{
Adição de Resíduos Orgânicos ao Substrato para Produção de Mudas de Café em Tubete
}

Sérgio Luiz Santana de Almeida, Instituto Federal de Educação, Ciência e Tecnologia do Sul de Minas Gerais, Campus Machado, sergiosantana@mch.ifsuldeminas.edu.br. Franciane Diniz Cogo, Universidade Federal de Lavras, Departamento de Ciência do Solo, francia-ne_diniz@hotmail.com. Bruna Oliveira Gonçalvest, Instituto Federal de Educação, Ciência e Tecnologia do Sul de Minas Gerais, Campus, brunaoliveira@hotmail.com. Bruno Teixeira Ribeiro, Instituto Federal de Educação, Ciência e Tecnologia do Sul de Minas Gerais, Campus Machado, ribeiro.bt@gmail.com. Katia Alves Campos, Instituto Federal de Educação, Ciência e Tecnologia do Sul de Minas Gerais, Campus Machado, katia@mch.ifsuldeminas.edu.br. Augusto Ramalho de Morais, Universidade Federal de Lavras, augustorm@dex.ufla.br

\section{RESUMO}

Com o objetivo de avaliar os efeitos dos substratos no desenvolvimento inicial de ca-feeiros (Coffea arabica L.) plantados em tubetes, foi conduzido, em viveiro de café no Institu-to Federal do Sul de Minas (IFSULDEMINAS), campus Machado, no sul de Minas Gerais. O delineamento experimental utilizado foi de blocos casualizados em esquema fatorial $3 \times 5$, com três repetições. Cada parcela foi constituída por três tubetes com capacidade volumétrica de $51 \mathrm{ml}$ cada. Os fatores em estudo foram os três genótipos de Coffea arabica (Catuaí Vermelho IAC 44, Catucaí Amarelo 2SL e Mundo Novo IAC 379-19) e as cinco adições ao substrato comercial foram: húmus de minhoca, esterco bovino de curral, esterco curtido de galinha, palha curtida de café (resíduos da máquina de beneficiamento) e, como testemunha, o substra-to comercial puro. Os tratamentos foram constituídos por $50 \%$ do produto comercial, $10 \%$ de vermiculita e $5 \%$ de areia grossa, adicionando-se aos $35 \%$ restantes os tratamentos citados anteriormente. Verificou-se a possibilidade de substituir nesta proporção o substrato comercial por fonte de material orgânico.

Palavras-chave: Coffea arabica, tubete, substrato.

\section{Coffee Seedlings Growing In Substrate Amended With Differentes Organic Residues}

\begin{abstract}
Aiming to evaluate the effects doe substrates in the initial development of coffee (Coffea arabica L.) planted in plas-tic tubes, was carried out at coffee nursery at the Federal Institute of Southern Minas IFSULDEMINAS - Machado Campus, located in southern Minas Gerais. The experimental design was randomized blocks in factorial scheme $3 \times 5$, with three replications. Each plot consisted of three tubes with a volume capacity of $120 \mathrm{ml}$ each, and the factors were the three genotypes of Coffea arabica (IAC Catuaí Red 44, Yel-low Catucaí 2SL and Mundo Novo IAC 379-19) and the five additions to commercial substrate were earthworm compost, farmyard manure, chicken manure and tanned, leathery coffee straw (waste processing machine) and as a witness, the pure commercial substrate. The treatments were to be composed of $50 \%$ of the commercial product, $10 \%$ vermiculite and $5 \%$ coarse sand, adding - if, in the remaining 35\% treatments mentioned previously. There was the possibility of replacing $35 \%$ of the substrate by commercial source of orga nic material.
\end{abstract}

Key words: Coffea arabica, tube, substrates. 


\section{INTRODUÇÃO}

A atividade cafeeira tem expressivo destaque na economia, havendo indícios de que os níveis de produção estão subindo gradualmente, nos diversos países produtores.

Estimativas divulgadas recentemente (ORGANIZAÇÃO INTERNACIONAL DO CAFÉ - OIC, 2010) indicam que a produção total do ano-safra de 2010/11 deve girar em torno de 133 a 135 milhões de sacas. Diante da grande produção e, conseqüentemente, da área plantada, e ainda, por se tratar de uma cultura perene, é totalmente relevante produzir mudas que se adaptem às condições climáticas, principalmente durante a transferência do viveiro para o campo. Assim, a produção de mudas de cafeeiro com qualidade é o início para se obter um bom stand na lavoura.

É de grande importância que na composição do substrato estejam presentes todos os nutrientes necessários para o desenvolvimento das plantas e que eles estejam disponíveis, além de apresentar aspectos como: grande porosidade, alta capacidade de troca catiônica, boa retenção de água, livre de pragas, patógenos e ser economicamente viável.

Vários materiais têm sido empregados na produção de mudas em tubetes, isoladamente ou em misturas, destacando-se a vermiculita, o esterco bovino, a "moinha" de carvão, a serragem, o bagaço de cana, a acícula e casca de pinus, a casca de eucalipto compos-tada, a casca de arroz calcinada, o húmus de minhoca e a turfa (CAMPINHO JUNIOR; IKEMORI; MARTINS, 1984; GUIMARÃES et al., 1998).

A principal dificuldade é aliar qualidade ao baixo custo na produção do substrato. Nesta técnica, apesar de usado em menor volume, são utilizados constituintes que apresentam custos mais elevados.

Considerando-se o custo de produção de mudas cafeeiras, o substrato é responsável por $38 \%$ do custo de produção (tubetes de $120 \mathrm{~mL}$ ), desprezandose o custo com a aduba-ção (GUIMARÃES et al., 1998). Assim, é necessário buscar novas estratégias de manejo que visem minimizar tais investimentos.

Diversas pesquisas estão sendo realizadas no intuito de verificar a eficiência de tecnologias alterna tivas na formação do substrato. No trabalho realizado com mudas de café em tubete utilizando esterco bovino na proporção de $80 \%$, adubado com Osmocote $®$, obteve-se maior altura de planta, massa seca de raízes e de parte aérea (ANDRADE NE-TO; MENDES; GUIMARÃES, 1999).

No estudo realizado com húmus de minhoca adicionado ao substrato artificial, na proporção de $80 \%$ ou em uso exclusivo (100\%) acrescido de fertilizante de liberação gradual, foi constatado aumento na área foliar das mudas de cafeeiro e, como conseqüência, acúmulo de massa seca, tanto na parte aérea quanto no sistema radicular. O uso de esterco bovino acima de $30 \%$ e de cama de peru, também acrescidos de fertilizante de liberação gradual, não alterou as características vegetativas das mudas de cafeeiro (DIAS; MELO; SILVEIRA, 2009).

$\mathrm{Na}$ pesquisa realizada com composto orgânico, cama de aviário, palha de café carbonizada, casca de arroz carbonizada e termofosfato acrescido de cinza, observou-se que mudas produzidas nos substratos mencionados não diferiram entre si quanto à altura, mas apresentaram diferença significativa quanto ao peso seco da parte aérea (MIRANDA; RICCI, 2001).

Tendo em vista a necessidade de encontrar um substrato economicamente viável para a formação de mudas em tubetes, com a realização deste trabalho buscou avaliar a eficiência de substratos alternativos para a produção de mudas de café.

\section{MATERIAL E MÉTODOS}

O trabalho foi realizado no viveiro de produção de mudas de café do Instituto Federal de Educação, Ciência e Tecnologia do Sul de Minas (IFSULDEMINAS), campus Machado, MG.

Adotou-se o delineamento em blocos inteiramente ca-sualizados, com três repeti-ções, em esquema fatorial $3 \times 5$, constituindo 15 tratamentos formados pelas combinações entre os fatores em estudo: três genótipos de Coffea arabica (Catuaí Vermelho IAC 44, Catucaí Amarelo 2SL e Mundo Novo IAC 19) e as quatro adições ao substrato comercial (húmus de minhoca, esterco bovino esterco de galinhas, palha de café) e como testemunha o substrato comercial puro, com os percentuais distribuídos conforme a Tabela 1.

Tabela 1. Caracterização das adições ao substrato comercial quanto ao percentual dos componentes do substrato.

\begin{tabular}{lllcl}
\hline & Resíduos orgânicos & Vermiculita (\%) \\
\hline A & Húmus de minhoca (35\%) & 50 & 10 & 5 \\
B & Esterco de bovino (35\%) & 50 & 10 & 5 \\
C & Esterco de galinha (35\%) & 50 & 10 & 5 \\
D & Palha de café (35\%) & 50 & 10 & 5 \\
E & - & 85 & 10 & 5 \\
\hline
\end{tabular}


As parcelas foram constituídas por três tubetes com capacidade volumétrica de $120 \mathrm{ml}$ cada um, e para a produção das mudas, foram colocadas, de acordo com o sorteio, duas sementes das cultivares Catuaí Vermelho IAC 44, Catucaí Amarelo 2SL e Mundo Novo IAC 379-19, respectivamente.

Quando as mudas atingiram o estágio palito de fósforo foi realizado desbaste deixando-se apenas uma planta por tubete, mantendo-as sob sombrite $(50 \%$ de passagem de luz) e irrigadas diariamente com uso de microaspersores, com vazão nominal de $60 \mathrm{~L} \mathrm{~h}-1$.

Após 180 dias à semeadura foram avaliadas as características: altura de planta, comprimento das raízes, número total de folhas, diâmetro do caule e a massa fresca e seca do sistema radicular e da parte aérea.

As médias foram submetidas ao teste de $\mathrm{F}$ ao nível de $5 \%$ de significância e aos testes de normalidade dos erros e de homocedasticidade de variâncias, respectivamente por meio dos testes de ShapiroWilks e Bar-tlett. Todos os testes foram realizados utilizando-se o programa "R" (R DEVELOPMENT CORE TEAM, 2008).
Os testes que validam os pressupostos da análise de variância, Shapiro-Wilks, para a normalidade e Bartlett, para a homocedasticidade de variâncias, atestaram tais pressupostos.

\section{RESULTADOS E DISCUSSÃO}

Para a validação da analise de variância foi aplicado os testes Shapiro-Wilks, para a normalidade e Bartlett para a homocedasticidade, que demostrou que as hipóteses são sa-tisfatórias; em seguida procedeu-se o teste de $F$ que indicou que não houve interação entre os fatores cultivares e substratos para nenhuma das características avaliadas, indicando que os fatores agem de maneira independente sobre tais características (Tabela 2).

Os resultados para ao substrato alternativos estão de acordo com os apresentados por Vallone et al. (2010), que também utilizaram, como fonte alternativa, material orgânico. Observou-se que o comportamento das mudas de cafeeiro em todos os tratamentos foi semelhante para as três cultivares em estudo.

Tabela 2. Resumos das análises de variância para as variáveis avaliadas no experimento sobre substratos alternativos para a produção de mudas de cafeeiro (Coffea arabica L.), em tubetes para as avaliações de crescimento de planta (Machado, MG, 2010).

\section{Teste de F}

Causas de Variação

Cultivares

Substrato

Bloco

Int. C x S

\begin{tabular}{|c|c|c|c|c|c|c|c|c|c|c|}
\hline & \multirow{3}{*}{ Altura } & \multirow{3}{*}{ Comp. } & & \multirow{3}{*}{$\begin{array}{l}N^{\circ} \text { de } \\
\text { folhas }\end{array}$} & \multicolumn{3}{|c|}{ Massas Verdes (g) } & \multicolumn{3}{|c|}{ Massas Secas (g) } \\
\hline & & & & & & Parte & & & Parte & \\
\hline & & & & & & raiz & & & raiz & Total \\
\hline 2 & 0,37 & 0,43 & 0,90 & 0,10 & 0,17 & 0,16 & 0,14 & 0,15 & 0,25 & 0,17 \\
\hline 2 & 0,76 & 0,65 & 0,36 & 0,70 & 0,64 & 0,77 & 0,65 & 0,77 & 0,26 & 0,70 \\
\hline 4 & 0,80 & 0,68 & 0.91 & 0,57 & 0,98 & 0,23 & 0,86 & 0,80 & 0,82 & 0,80 \\
\hline 8 & 0,92 & 0,68 & 0,77 & 0,93 & 0,95 & 0,93 & 0,97 & 0,71 & 0,42 & 0,69 \\
\hline
\end{tabular}

As médias observadas para as variáveis alturas, comprimento radicular, número de folhas, diâmetro, massa verde radicular, massa seca aérea, massa verde da parte aérea, massa seca da parte aérea, massa verde total e massa seca total de mudas de cafeeiro, em função de diferentes substratos e cultivares, para as cultivares e para os diferentes substra-tos, não apresentaram diferença significativa estão representadas nas Figuras 1 e 2 .

Trabalhos realizados buscando-se alternativa para o substrato para a produção de mudas de cafeeiros. A grande maioria deles discorda quanto ao resultado encontrado, por apresentar diferenças entre o substrato comercial e o alternativo. Estes substratos não são os mesmos utilizados neste trabalho (ANDRADE NETO, et al, 1999; CUNHA, 2002). as fontes de substratos obtidos por diferentes fontes de matéria orgânica, destaca-se a eficiência dos compostos utilizados nas características avaliadas. Andrada Neto, Mendes e Guimarães (1999) encontraram o mesmo resultado comparado ao produto comercial quanto ao uso da fonte de matéria orgânica de húmus de minhoca, o que representou uma substituição de $35 \%$ do substrato. Já para o esterco bovino os resultados são contraditórios.

Da mesma forma, Dias, Melo e Silveira (2009), ao adicionarem $40 \%$ de cama de peru ao substrato artificial, constataram que essa adição favoreceu o desenvolvimento das mudas do cafeeiro, enquanto que o esterco bovino ao ser acrescido ao substrato artificial, independente de sua proporção, prejudicou o desenvolvimento das mudas. 

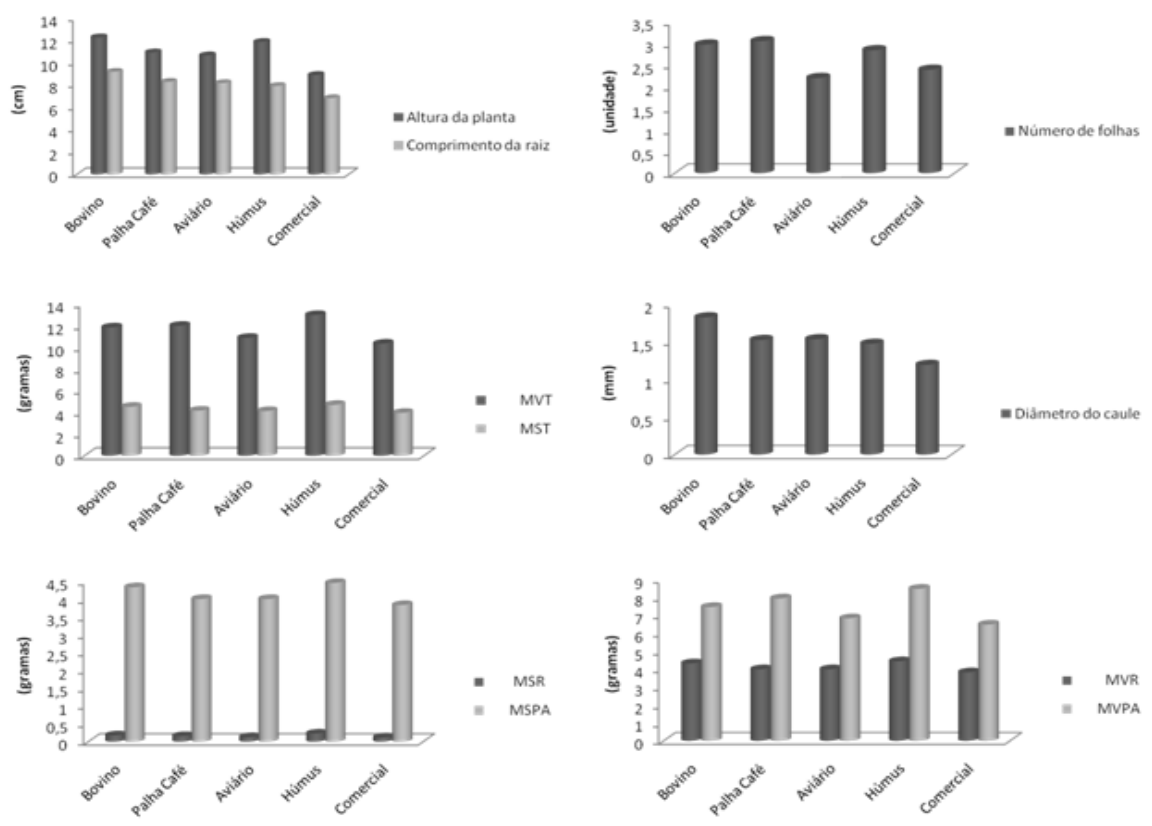

Figura 1 - Representação gráfica das avaliações - valores médios das características de crescimento de altura da planta, comprimento da raiz, diâmetro de caule, massa verde radi-cular (MVR), massa seca radicular (MSR), massa verde da parte aérea (MVPA), massa seca da parte aérea (MSPA), massa verde total (MVT) e massa seca total (MST) de mudas de cafeeiros em função de diferentes cultivares. IFSULDEMINAS, Machado, MG, 2009.
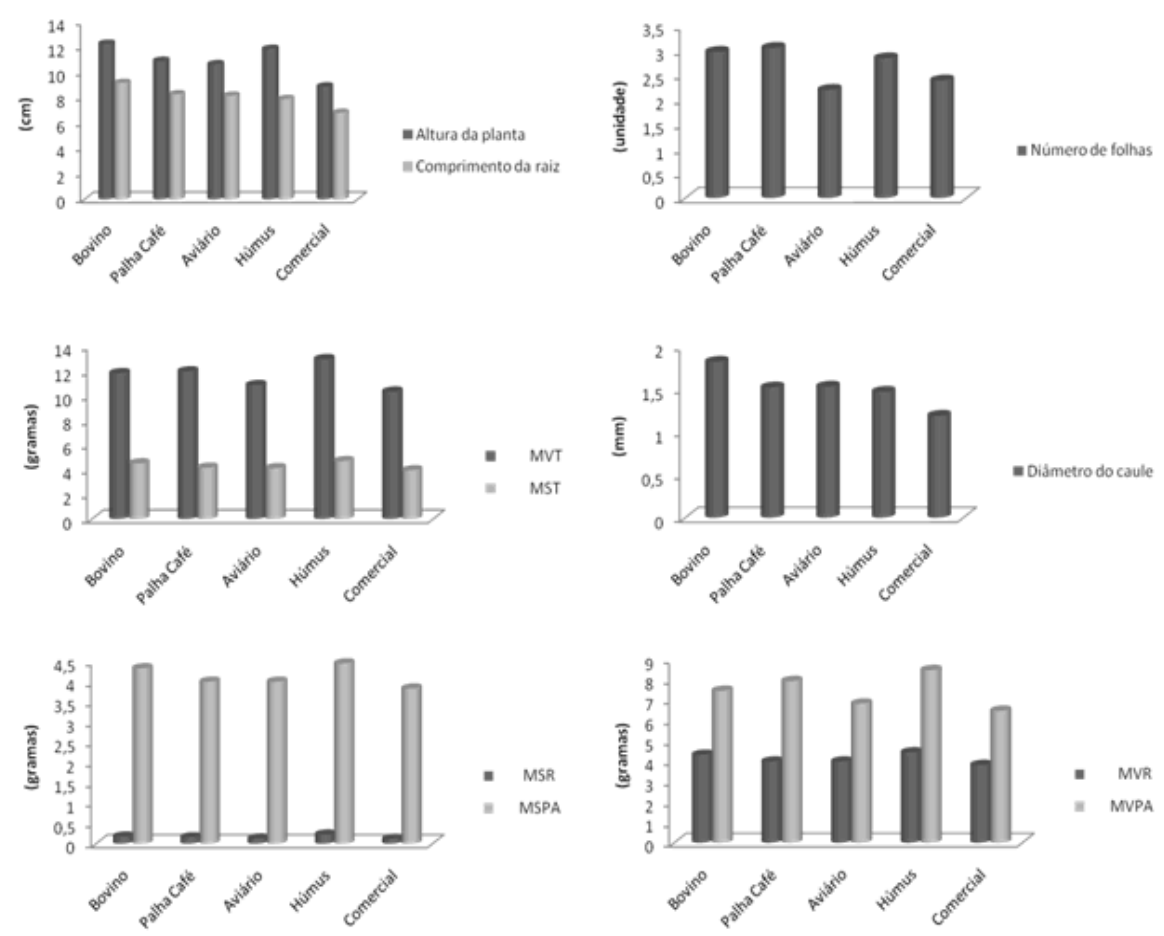

Figura 2 - Representação gráfica das avaliações - valores médios das características de crescimento de altura, comprimento da raiz, diâmetro de caule, massa verde radicular (MVR), massa seca radicular (MSR), massa verde da parte aérea (MVPA), massa seca da parte aérea (MSPA), massa verde total (MVT) e massa seca total (MST) de mudas de cafeeiros, em função de componentes do substrato. IFSULDEMINAS, Machado, MG, 2009. 


\section{CONCLUSÕES}

O uso de fontes de matéria orgânica aviária, bovino e húmus de minhoca na substi-tuição de $35 \%$ do substrato tradicional, pode ser uma alternativa para a fertilização do substrato para mudas de cafeeiro em tu-bete, pois as características de crescimento não diferem quando comparados ao substrato comercial puro.

\section{AGRADECIMENTO (S)}

Os autores agradecem ao Instituto Federal de Minas Gerais (IFSULDEMINAS), campus Machado, pela ajuda na condução experimental; à Cooperativa dos Alunos, COE-TAGRI pelo apoio financeiro e a FAPEMIG pela concessão da bolsa de iniciação científica e a empresa AGROPLASTICOS pela doação dos tubetes.

Agradecem também a Deus, pelo privilégio de ter convivido e trabalhado com a bolsista do programa BIC-Jr. FAPEMIG Bruna Oliveira Gonçalves uma das participantes deste projeto e dedicam a sua conclusão em sua memória.

\section{REFERÊNCIAS}

ANDRADE NETO, A. de; MENDES, A. N. G.; GUIMARÃES, P. T. G. Avaliação de substratos alternativos e tipos de adubação para a produção de mudas de cafeeiro (Coffea arabica L.) em tubetes. Ciência e Agrotecnologia, Lavras, v. 23, n. 2, p. 270-280, 1999.

CAMPINHOS JUNIOR, E; IKEMORI, Y. K; MARTINS, F. C. G. Determinação do meio de crescimento mais adequado à formação de mudas de Eucaliptus sp. e Pinus $s p$. em recipientes plásticos rígidos. In: SIMP ÓSIO INTERNACIONAL: MÉTODOS DE PRODUÇÃO E CONTROLE DE QUALIDADE DE SEMENTES E MUDAS FLORESTAIS, 1., 1984, Curitiba. Anais... Curitiba:

UFPR, 1984. p. 350-365.

CUNHA, R. L.; SOUZA, C. A. S.; ATAUALPA DE ANDRA-DE NETO, A.; MELO, B. AVALIAÇÃO DE SUBSTRATOS E TAMANHOS DE RECIPIENTES NA FORMA-ÇÃO DE MUDAS DE CAFEEIROS (Coffea arabica L.) EM TUBETES. Ciência e Agrotecnologia, Lavras, v.26, n.1, p.7-12, 2002.

DIAS, R.; MELO, B. D.; SILVEIRA, M. D. Fontes e proporções de material orgânico para a produção de mudas de cafeeiro em tubetes. Ciência e Agrotecnologia, Lavras, v. 33, n. 3, p. 758-764, maio/jun. 2009.
GUIMARÃES, P. T. G.; et al., Produção de mudas de cafeeiros em tubetes. In: TORRES, G.; et al., (Ed.). Cafeicultura: tecnologia para produção. Belo Horizonte: EPAMIG, 1998. p. 98-109.

MIRANDA, S. C.; RICCI, M. dos S. F. Substratos alternativos para mudas em tubetes. In: SIMPÓSIO DE PESQUISA DOS CAFÉS DO BRASIL, 2., 2001, Vitória. Anais... Vitó-ria: EMBRAPA, 2001. 2633-2638.

ORGANIZAÇÃO INTERNACIONAL DO CAFÉ. Preços do café devem recuar com chegada da safra 2010/11. 2010. Disponível em: <http://www.integrada.coop.br/ notas/502/OIC:-preço-do-cafe-devem-recuar-comchegada-da-safra-2010e11>. Acesso em: 19 ago. 2010.

R DEVELOPMENT CORE TEAM. R: A language and environment for statistical computing. Vienna, Austria: $R$ Foundation for Statistical Computing, 2008. ISBN 3-900051-07-0.

VALLONE, H. S.; GUIMARÃES, R. J.; MENDES, A. N. et al. Efeitos de recipientes e substratos utilizados na produção de mudas de cafeeiro no desenvolvimento inicial em casa de vegetação, sob estresse hídrico. Ciência Agrotecnologia, Lavras, v. 34, n. 2, p. 320-328, 2010. 